\title{
Research on the Mechanism of Sediment Formation of Al Compounds on Platinum Electrodes in Inner Water Cooling Systems for HVDC Converter Valves
}

\author{
Zeming Yang ${ }^{1}$, Daoyu Li ${ }^{2}$, Xuezhong Liu ${ }^{3, *}$, Baihao Gong ${ }^{3}$, Xiuying Jiao ${ }^{4}$, Shicai Lu ${ }^{2}$, \\ Chenxing Wang ${ }^{3}$, Yi Jiang ${ }^{2}$, Huaping $\mathrm{Xu}^{2}$, Yi Chen ${ }^{2}$ \\ ${ }^{1}$ China Southern Power Grid Company Limited, Guangzhou 510623, China \\ ${ }^{2}$ Guiyang Bureau, Extra High Voltage Power Transmission Company, China Southern Power Grid \\ Company Limited, Guiyang 550081, China \\ ${ }^{3}$ State Key Laboratory of Electrical Insulation and Power Equipment, Xi'an Jiaotong University, Xi'an \\ 710049, China \\ ${ }^{4}$ Xi'an XD Power Systems Company Limited, China XD Group, Xi'an 710075, China \\ *E-mail: xliu@xjtu.edu.cn
}

Received: 21 July 2021 / Accepted: 8 October 2021 / Published: 10 November 2021

The reliable operation of high voltage direct current (HVDC) converter valves is threatened by the problem of sediment deposition on platinum electrodes in inner water cooling systems. In this paper, simulated corrosion experiments of aluminium heat sinks and simulated deposition on pin-type platinum electrodes were carried out in the laboratory. Based on thermodynamic theory, the existing forms of $\mathrm{Al}(\mathrm{III})$ species in cooling water were revealed through theoretical calculations. According to the electrophoretic deposition, the sediment deposition process on the platinum electrodes was numerically simulated by COMSOL software simulation. The research results show that the $\mathrm{pH}$ value has a great influence on the existing forms of Al(III) species in cooling water. More importantly, the electrical properties of aluminum reaction species in inner valve cooling systems are dominated by environmental $\mathrm{pH}$ values rather than the original corrosion reactions, thus leading to the phenomenon that sediment depositions are found only on platinum electrodes connected as anodes in engineering practice. Both the simulated experiments and the numerical calculation also indicate that the deposited sediment on the platinum electrode is rod-shaped and that the growth rate of sediment thickness decreases with time. This research can play an important role in clarifying the phenomenon and mechanism of deposition on platinum electrodes in HVDC converter valves.

Keywords: HVDC, Converter valve, Cooling system, Platinum electrodes, Sediment deposition 
(C) 2021 The Authors. Published by ESG (www.electrochemsci.org). This article is an open access article distributed under the terms and conditions of the Creative Commons Attribution license (http://creativecommons.org/licenses/by/4.0/). 